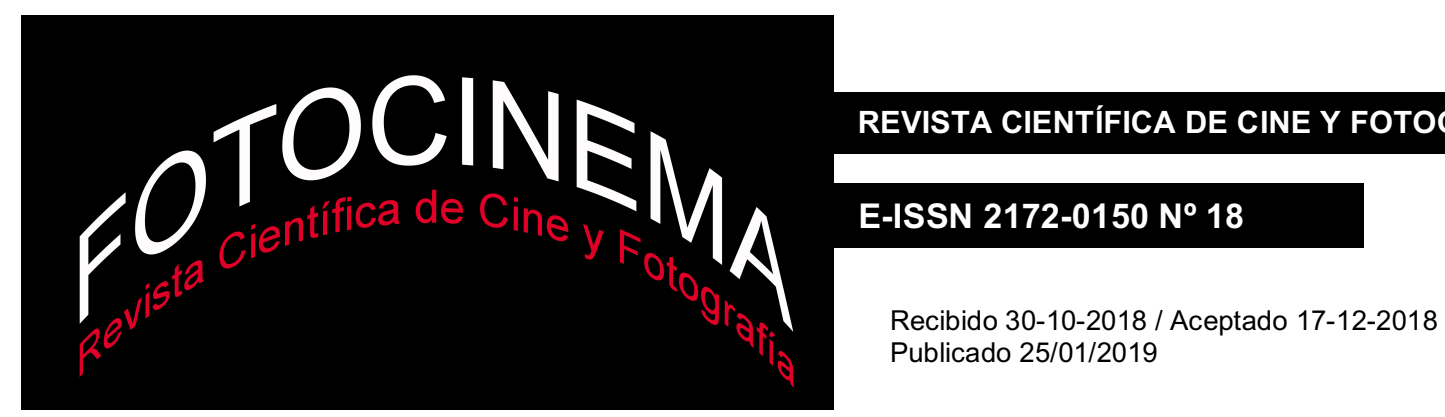

\title{
De lo fotográfico a la fotografía digital contemporánea: la imagen en el intercambio discursivo
}

\section{From the photographic to contemporary photograpy: The image in the discursive interchange}

\author{
Leticia Rigat \\ Universidad Nacional de Rosario / CONICET, Argentina \\ letirigat@hotmail.com
}

\section{Resumen:}

En el presente trabajo nos proponemos reflexionar sobre los cambios en los modos de producción, circulación y recepción de la fotografía, a partir del surgimiento de las tecnologías digitales y los nuevos medios de comunicación con base en Internet. En este sentido, buscamos indagar sobre el impacto que las nuevas tecnologías generaron en el pensamiento sobre la fotografía (con el paso de lo analógico a lo digital) y sobre sus usos sociales (a partir la desmaterialización de la imagen y los nuevos medios digitales de comunicación). Transformaciones que hacia el cambio de siglo dieron lugar a los diagnósticos de la muerte de la fotografía y la llegada de una nueva Era: la de la postfotografía, en el contexto de una nueva cultura visual - digital.

En la actualidad la fotografía más que una forma de testimonio y memoria (como fueron sus funciones primordiales durante el siglo XX), adquiere una función comunicativa de primer orden. Compartida, comentada, intercambiada, la fotografía contemporánea es hoy un mensaje en sí mismo dentro del intercambio discursivo cotidiano.

\begin{abstract}
:
In this article, we shall reflect on the changes in the ways of production, circulation and reception of photography since the emergence of the digital technologies and the new Internet-based media. With respect to this, we shall reflect on the impact that the new technologies caused in the way of thinking about photography (change from analogical to digital) and its social uses (from the dematerialization of the image and the new digital media). Transformations that towards the change of the century led to the diagnosis of death of photography and the arrival of a new age: the post-photography age, in the context of a new visual digital culture.

Nowadays, photography is not only a way of testimony and memory (these were its fundamental functions during the 2oth century) but it also gains a new first-rate communicative function. Shared, commented and interchanged, contemporary photography is a message in itself in the daily discursive interchange.
\end{abstract}

\section{Palabras clave:}

Fotografía; postfotografía; nuevos medios de comunicación; cultura digital.

Keywords:

Photography; Postphotography; New media; Digital culture. 


\section{Introducción}

En el presente trabajo nos proponemos un estudio teórico sobre los cambios en la fotografía a partir de la digitalización de su dispositivo y el surgimiento de los nuevos medios de comunicación con base en Internet. A través de una lectura crítico-interpretativa, nos abocamos al análisis de distintas teorías sobre la fotografía, particularmente aquellas que plantean la especificidad de la imagen fotográfica a partir de su carácter indicial, el funcionamiento del dispositivo y la representación de lo real. En relación a lo anterior, revisamos los debates que a partir de la década del noventa, con la aparición de las tecnologías digitales y los nuevos medios de comunicación, plantearon la muerte de la fotografía y la era de la postfotografía. Finalmente, proponemos algunas reflexiones e interrogantes sobre la etapa actual del pensamiento sobre la fotografía digital contemporánea, las transformaciones en las prácticas fotográficas, y en los modos de circulación, a partir de los nuevos medios de comunicación.

Hacia fines del siglo XX, y principalmente tras el cambio de siglo, vivimos una etapa de transición profunda en las comunicaciones. Las nuevas tecnologías digitales y los nuevos medios de comunicación con base en Internet prometían una transformación rotunda en el Sistema de los Medios Masivos (Carlón, 2009) basados en dispositivos técnico-indiciales. Discursos extincionistas diagnosticaban la muerte de los medios de masas (como la prensa, la radio y la televisión) y la entrada a una nueva era de las comunicaciones. Sin duda, las nuevas tecnologías han modificado profundamente nuestra mediatización, tanto en la producción, circulación como recepción de los mensajes; y con ello los medios tradicionales han mutado en sus formas, pero lejos estamos de su desaparición.

Los medios de comunicación digitales han producido cambios sustanciales en la relación que el hombre mantiene con el mundo, con la emergencia de nuevas relaciones con el espacio y el tiempo; sujetos interconectados productores de mensajes; novedosas formas de acceso a la información y maneras de producirla; etcétera. Nuevos modos de interrelación que van caracterizando nuestra contemporaneidad.

En el caso específico de la fotografía, en los años 1990, tomó forma el debate sobre los impactos que la digitalización traería sobre las prácticas fotográficas basadas 
en el soporte químico; se anunció la pérdida de la credibilidad de la imagen (de su capacidad de ofrecernos un registro directo de lo real); y con ello se anunció su muerte y la llegada de una nueva Era: la de la postfotografía (Mitchell, 1992; Mirzoeff, 2003 [1999]; Ritchin, 2010; Robins, 1997; Fontcuberta, 2007).

Sin duda, los cambios en la fotografía han sido muchos, y las transformaciones en el dispositivo fotográfico pueden pensarse como un punto de inflexión para reflexionar sobre el lugar que la fotografía tiene en la contemporaneidad, en la nueva cultura digital y los nuevos medios de comunicación.

En este sentido, se torna necesario analizar las mutaciones que forjaron las actuales condiciones de producción, circulación y recepción de la imagen fotográfica; considerando los cambios en la naturaleza de la imagen y las nuevas significaciones sociales sobre la fotografía. En este punto parece interesante revisar ciertas teorías sobre la especificidad de la imagen fotográfica analógica, algunos ejes del debate de las consecuencias de la digitalización del dispositivo y los nuevos medios de comunicación, para poder reflexionar sobre el lugar que la fotografía ocupa hoy en las comunicaciones de miles de usuarios de redes sociales, donde la imagen acompaña a la palabra casi de manera constante, y se transforma en un mensaje en sí mismo en los intercambios cotidianos.

\section{La imagen huella}

Si miramos retrospectivamente la historia de la fotografía es posible observar la continua reevaluación de su estatuto y sus usos sociales. Muchos de estos cuestionamientos han girado en torno a dicotomías como: dispositivo - medio; técnica de registro - medio de expresión; documento - arte; entre otras. En ellas subyace el lugar primordial que ha tenido el hecho de que la imagen es el resultado de la mediación de un dispositivo técnico. No nos es posible aquí detenernos en cada uno de estos debates, no obstante a los fines de nuestras reflexiones, nos gustaría revisar algunos lineamientos de ciertas teorías que buscaron definir la especificidad de la fotografía, en base a su diferencia con otros medios de producción de imágenes, que ponen en el centro la noción de dispositivo técnico y el concepto de lo fotográfico como objeto teórico. 
Desde esta perspectiva, Roland Barthes, reflexionando sobre qué diferenciaba a la fotografía de otros medios de producción de imágenes, afirmaba que contrariamente a las imitaciones "nunca puedo negar en la fotografía que la cosa haya estado allí. Hay una doble posición conjunta: de realidad y de pasado" (Barthes, 2005, p. 135), a esta cualidad le atribuye la esencia de la fotografía, su noema: "esto ha sido". Afirmando con ello la posición realista y constatativa de la imagen, la fotografía es literalmente la huella del referente necesariamente real que se ha encontrado delante del dispositivo, y sin el cual no habría fotografía.

Contemporáneamente, Susan Sontag destaca el carácter de evidencia de la fotografía y su articulación con el conocimiento de los acontecimientos: "Algo que conocemos de oídas, pero de lo cual tenemos dudas parece irrefutable cuando nos los muestran en una fotografía [...] una fotografía se considera prueba incontrovertible de que algo determinado sucedió" (Sontag, 1977, p. 15-16). La fotografía resultaría, de esta manera, un modo de certificar la experiencia, pues siempre delante de una fotografía debemos admitir la existencia de lo que en ella se nos muestra más allá de la verdad o falsedad del acontecimiento fotografiado. Podemos observar en este tipo de análisis una distinción que Rosalind Krauss (2002) plantea entre el estudio de la fotografía como objeto estético, histórico y sociológico, y el estudio de lo fotográfico como objeto teórico. Un estudio sobre la especificidad de la imagen fotográfica que pone en primer lugar al dispositivo que permite crear una imagen a partir de la contigüidad física con lo que representa, como un índice en el sentido de la teoría de Charles S. Peirce. En este sentido, el propio Peirce señala:

Las fotografías, especialmente las fotografías instantáneas, son muy instructivas, porque sabemos que en ciertos aspectos son exactamente iguales a los objetos que representan. Pero esta semejanza se debe a que las fotografías han sido producidas en circunstancias tales que estaban físicamente forzadas a corresponder punto por punto a la naturaleza (Peirce, 1987, p. 264).

En 1987 Jean-Marie Schaeffer publica La imagen precaria. Del dispositivo fotográfico en el que propone un estudio pragmático de la fotografía, partiendo del postulado de que un signo no tiene más existencia que para un interpretante, al menos virtual, buscando captar la imagen fotográfica en la dimensión de su circulación social, no real sino virtual. El autor, retomando la definición de signo 
de Peirce (1987), advierte que no debemos olvidar que la fotografía se constituye mediante la combinación de tres dimensiones: representamen, interpretante y objeto; según lo cual: el signo (imagen foto) representa algo (su objeto) para alguien (su interpretante) quien hará predominar en el acto receptivo la temporalidad o la espacialidad de la imagen fotográfica. Por lo anterior, en la fotografía, el representamen puede ser o un 'índice icónico' o un 'icono-indicial', lo cual pone de manifiesto el carácter ambiguo del signo fotográfico que se halla en una tensión constante entre la función indicial y la presencia icónica. Es decir, en términos de Peirce: un “«Icono» o Signo que representa su Objeto al parecérsele” y un “"Índices» o Signos que representan sus Objetos al estar realmente conectados con éstos" (Peirce, 1987, p. 105).

A partir de lo anterior, Schaeffer explica que hay una distancia temporal en la fotografía, entre el acto de producción y la recepción, distancia que nace del saber que "el icono es la retención visual de un instante espacio - temporal real, el tiempo fotográfico es [...] el tiempo físico (el momento y la duración) de la formación de la impresión” (Schaeffer, 1990, p. 45).

De esta manera, para Schaeffer, la iconicidad de la fotografía se debe a la función indicial, y es posible reconocer dicha cualidad puesto que:

Disponemos además de un saber referente al funcionamiento del dispositivo fotográfico, aquello que he propuesto llamar el saber del arché: la imagen se convierte en un indicio en cuanto sabemos que ésta última es el efecto de irradiaciones precedentes del objeto [...] (Schaeffer, 1990, p. 44).

Desde un sentido similar, Philippe Dubois (2008) afirma que la especificidad de la fotografía hay que definirla a partir de su génesis técnica (Bazin, 2004). En su teoría, la imagen fotográfica y el acto que la define son indiscernibles, poniendo en primer lugar la reflexión sobre el dispositivo y la idea de traza. La fotografía, para Dubois, se sitúa en la categoría de signos que Peirce define como index:

signos que mantienen o mantuvieron en un momento determinado del tiempo, con su referente (su causa) una conexión real de contigüidad física, de co-presencia inmediata, mientras que los iconos se definen más bien por una simple relación de semejanza y los símbolos por una relación de convención general (Dubois, 2008, p. 56). 
Desde estos enfoques, la imagen fotográfica se distinguiría de otras imágenes fijas a partir de la presencia del dispositivo técnico indicial que permite la obtención de una imagen huella. Y en este punto podemos destacar la idea de corte, que hace que en el acto fotográfico la imagen se constituya a partir del cruce espacio - temporal, en el que se fija un instante arrancado de la duración. En la imagen en movimiento, explica Schaeffer, el desarrollo se percibe como un flujo actual, abriendo el tiempo como presencia; en cambio la imagen fotográfica en su fijeza, abre una distancia temporal entre el momento de su producción y el momento de su recepción, haciendo surgir el tiempo como pasado. En su acto fundador, la imagen foto interrumpe, detiene y fija la duración en un solo instante. En cuanto a la espacialidad, fracciona, aísla y capta una porción de la extensión, se trata de una fracción de espacio seleccionada, enmarcada, "un espacio a tomar (o dejar), una selección en el mundo, una sustracción que se opera en bloque” (Dubois, 2008, p. 158).

Por otra parte, estas características técnicas, llevan a pensar también los procesos de significación de la imagen y con ellos los usos sociales de la fotografía. La imagen fotográfica es un artefacto cultural, además de un dispositivo que permite la huella lumínica del referente, resulta de la elección del fotógrafo (de una multiplicidad de elecciones para ser más precisos, como la escena, el encuadre, las distancias focales del objetivo, las condiciones lumínicas, la apertura del diafragma, etcétera) que responde ya a condiciones culturales y saberes adquiridos. Pero asimismo, en la recepción intervienen construcciones culturales que permiten interpretar la imagen en relación a lo que ella nos muestra, su espacio de circulación (dónde vemos esa fotografía), y el hecho mismo de que es una imagen fotográfica (el conocimiento del arché explicitado por Schaeffer). Un conjunto de saberes que permiten crear e interpretar a la fotografía, en los que subyace el conocimiento de la naturaleza misma de la imagen, de su modo de construcción -en el que se genera una relación inmediata entre la imagen y lo que muestra a través de la huella-. Se abre aquí un punto importante para pensar los procesos de significación en la fotografía analógica: la distancia temporal entre la toma fotográfica y su visionado tras el proceso de revelado y copiado. Una distancia que nos remite a la idea de pasado y realidad. 
La fotografía, a diferencia de las obras de las artes plásticas, opera a través de un corte espacio - temporal; nos devuelve así la huella del referente, pero liberado de las contingencias temporales. En relación a esto, John Berger advierte que la fotografía es una extraña invención puesto que su materia prima es la luz y el tiempo:

Una fotografía detiene el flujo del tiempo en el que una vez existió el suceso fotografiado. Todas las fotografías son del pasado, no obstante en ellas un instante del pasado queda detenido de tal modo que, a diferencia de un pasado vivido, no puede nunca conducir al presente. Toda fotografía nos presenta dos mensajes: un mensaje relativo al suceso fotografiado y otro relativo a un golpe de discontinuidad (Berger, 1998, p. 86).

El primer mensaje se manifiesta como una evidencia de las apariencias de las cosas y/o del suceso fotografiado, y en ello no hay ninguna ambigüedad: la fotografía es la impresión directa de la luz, la huella del suceso. Ahora bien, advierte Berger, en la discontinuidad del momento registrado y el momento de mirar surge la ambigüedad. Dicha ambigüedad refiere al significado de lo que la fotografía nos muestra. El corte constitutivo del acto fotográfico, separa a la imagen del desarrollo del acontecimiento, del paso del tiempo:

Sin una historia, sin un despliegues, no hay significado. Los hechos, la información no constituyen significados en sí mismos. [...] Un instante fotografiado sólo puede adquirir significado en la medida en que el espectador pueda leer en él una duración que se extiende más allá de sí mismo. Cuando encontramos una fotografía con significado, le estamos dando un pasado y un futuro (Berger, 1998, p. 89).

Berger afirma que necesitamos un título para comprender el sentido de lo que las imágenes nos muestran, principalmente, aunque no únicamente, en las fotografías de circulación pública, puesto que en el ámbito privado muy a menudo las imágenes remiten al recuerdo y a la memoria (aunque sea adquirida por el relato) del grupo social al que pertenecen. Asimismo, suma, que la significación del título que acompaña la imagen depende del sentido de la historia que testimonia. De esta manera, Berger destaca el vínculo estrecho entre las imágenes y las palabras:

En la relación entre una fotografía y las palabras, la fotografía reclama una interpretación y las palabras la proporcionan la mayoría de las veces. La 
fotografía, irrefutable en tanto que evidencia, pero débil en significado, cobra significado mediante las palabras. Y las palabras, que por sí mismas quedan en el plano de la generalización, recuperan una autenticidad específica gracias a la irrefutabilidad de la fotografía (Berger, 1998, p. 92).

Desde este punto de vista, la relación de la imagen fotográfica con la palabra se torna necesaria. En términos similares, Schaeffer afirma que cualquier prueba es pertinente únicamente en relación con una teoría y un corpus de hipótesis explícitas y más concretamente en el marco de una experiencia cuyos diferentes parámetros sean controlados por el experimentador, la fotografía en su uso canónico de registro lo que hace es transmitirnos "una visión casi perceptiva referente a un estado de hecho o una entidad del universo perceptivo humano" (Schaeffer, 1990, p. 62).

Como explica Schaeffer, la imagen fotográfica es auto-identificatoria, y es al mismo tiempo humanamente motivada, su existencia obedece a una finalidad interpretativa, la del fotógrafo y la del receptor. La actividad de quien realiza la fotografía y la del receptor no se corresponden en cuanto al sentido, el primero trabaja desde su motivación y el segundo integrando la imagen a su propio universo interpretativo. Y en todo caso, la interpretación depende de una información contextual.

Desde esta perspectiva, Sontag afirma que mediante las fotografías no comprendemos nada, las fotos no explican nada en sí mismas, esto es una función del tiempo y la fotografía ha sido arrancada de la duración, es decir, el corte que las funda rompe con el eje de la duración real: "en rigor, nunca se comprende nada gracias a una fotografía, desde luego, las fotografías llenan lagunas en nuestras imágenes mentales del pasado y el presente” (Sontag, 1977, p. 33), la comprensión se basa en lo temporal, sólo lo narrativo puede permitirnos comprender.

Estas reflexiones, por las que hemos pasado resumidamente, permiten pensar algunas cuestiones claves que caracterizaron a la fotografía en el siglo XIX, hasta por lo menos las últimas décadas del siglo XX. Se trata de ciertas concepciones sociales que hacían de la fotografía una forma de certificación, de constatación de un acontecimiento (público o privado) o de la existencia de una entidad, mediada 
por la presencia de un dispositivo técnico que permitía capturar las huellas de lo real.

Los estudios descriptos anteriormente repararon principalmente en las características de la fotografía como dispositivo. No obstante, podemos decir también que la fotografía es un medio. Punto importante que destacó Eliseo Verón (en discusión con Barthes) y que resulta un análisis muy rico para pensar la situación actual.

En este sentido, Verón (1997) especifica que la imagen no es un imperio autónomo sino que se halla en dependencias que reglamentan la significación en el seno de la sociedad (haciendo con esto último, referencia a una semiología general que desempeñaría una postura opuesta a la que caracterizó a la deriva estructuralista y el reduccionismo lingüístico). Partiendo desde aquí, advierte que el haber estado allí de Barthes es en realidad una operación de quien observa la fotografía y no una operación contenida en la imagen misma, y que la temporalidad de la fotografía puede neutralizarse e interpretarse más bien como un estar allí (en el momento actual).

Retomando La cámara lúcida de Barthes, Verón afirma que: "el término fotografía que define una técnica y la identificación de un soporte técnico no basta para definir una discursividad social” (Verón, 1997, p. 56). Y advierte que Barthes habla de la fotografía en general, sin distinciones y sin especificar tres discursividades fotográficas a las que en realidad está haciendo referencia, estas son: la fotografía artística, las fotografías que resultan de la utilización privada de la técnica y la fotografía de reportaje.

A partir de ello, Verón se interroga: ¿cuál es el rango que le corresponde a ese objeto técnico que da lugar a diferentes utilizaciones $\mathrm{y}$, en consecuencia, a diferentes discursividades sociales? ¿Es sólo un objeto previo, anterior y exterior a la producción de sentido (que ya sería siempre discursiva)? ¿O bien constituye, como tal, una especie de núcleo semiótico? Retomando el noéma de la fotografía, Verón responde que Barthes creía en este núcleo semiótico y a partir de ello es que destaca el carácter referencial de la imagen fotográfica (su cualidad temporal de pasado y de realidad).

Refiriéndose a los medios modernos, Verón especifica que en ellos lo fundamental es el presente, la actualidad de la imagen, el él está allí más que el 
haber estado allí (Verón, 1997, p. 59). Afirma con ello que el noema de Barthes es un hecho técnico, y que el esto ha sido cobra valor en el uso privado de la imagen, pero en el ámbito público la fotografía se articula con modalidades de lo reciente.

A partir de lo especificado en los párrafos precedentes podemos observar que Verón puntualiza el papel central que el automatismo de la fotografía adquiere en la teoría de Barthes, pero argumenta que finalmente son las prácticas sociales, la discursivización posterior de la imagen las que determinan al medio. En este sentido Verón neutraliza al dispositivo, cuestión que es en realidad esencial para comprender los procesos de reconocimiento de la fotografía como imagen distinta a las producidas por otros medios de representación. De alguna manera, las observaciones de Verón, sirven más que para 'contradecir' a Barthes, para pensar el momento actual de la fotografía y los nuevos medios de comunicación donde la circulación de la imagen se piensa desde esa 'actualidad' de la fotografía y su irrupción en las redes; ya no se trata de un 'estuve ahí' sino de un 'estoy aquí' (en tal lugar y en las redes). No obstante, en su especificidad, la imagen fotográfica es siempre de un instante pasado, el propio Verón en su último libro La semiosos social, 2 (2013) destaca que: "la fotografía fue una primera materialización del tiempo, bajo la forma de la captación del instante fugaz que, lenta e inexorablemente, se va transformando en pasado" (Verón, 2013, p. 249).

Consideramos que ciertas observaciones sobre la discursivización de la imagen fotográfica de Verón, permiten reflexionar sobre las modalidades de lo reciente en los nuevos medios de comunicación, un punto central, no sólo en la circulación de las imágenes a través de las redes sociales sino en los propios procesos de producción y recepción de las imágenes, sobre ello volveremos al final. Primero nos parece importante revisar algunos debates que surgieron a partir de las tecnologías digitales.

\section{La imagen digital}

En los años 1990, y principalmente tras el cambio de siglo, comenzaron a tomar forma los debates sobre las consecuencias que las tecnologías digitales y los nuevos medios de comunicación traerían sobre las prácticas fotográficas basadas en el soporte analógico. Un debate que tuvo lugar en el contexto general en el que 
los discursos extincionistas iban anunciando la muerte de los medios técnico indiciales (televisión, prensa gráfica, fotografía, cine, radio) (Carlón y Scolari, 2009).

Específicamente en cuanto a la fotografía, dichos debates estuvieron estrechamente relacionados a los cambios en el dispositivo y con ello en los modos de interpretar a la imagen fotográfica como representación directa de lo real. Las reflexiones pasaban de considerar una imagen analógica basada en materiales foto-sensibles y procesos foto-químicos, a una imagen digital basada en un código numérico.

En cuanto a los debates sobre los cambios tecnológicos en los modos de producir imágenes pueden observarse distintas posturas: un enfoque más particular que se preocupa por los cambios en los modos tradicionales en las prácticas de representación visual; y otro más general en relación a las tecnologías, la cultura visual, la ciencia y la comunicación.

En cuanto a la fotografía, Martín Lister (1997) describe dos perspectivas, la primera centrada en cómo los nuevos procedimientos tecnológicos socavan una forma de representación visual esencial en la experiencia de las culturas modernas: la fotografía, y a partir de lo cual se teme por la 'posible desaparición' de las habilidades, la función artesanal, y el rol social del fotógrafo. Y una segunda postura que agrupa reflexiones en torno a cómo el paso de la imagen fotomecánica a construcciones digitales inmateriales produce transformaciones en la cultura visual. De esta manera, se afirma que lo que se pone en juego en la actualidad es mucho más que un cambio tecnológico en el modo de crear las imágenes, se trataría de un cambio de Era, con nuevas formas de pensar el mundo y representarlo (Lister, 1997).

Consideramos, al igual que Lister, que el debate más particular sobre los desplazamientos de las prácticas fotográficas por el uso de las tecnologías digitales, debe incluirse en el discurso más global sobre el cambio de época y hacer converger los dos niveles de análisis. Esta convergencia de pensamiento en torno a las tecnologías y una nueva cultura visual puede verse claramente en autores como William Mitchell (1992), Nicholas Mirzoeff (2003), Fred Ritchin (2010), Kevin Robins (1997) y Joan Fontcuberta (2012), quienes plantean el fin de la fotografía y la entrada a una nueva Era, la de la postfotografía, asociada a la 
emergencia de una nueva cultura de la imagen y el nacimiento de nuevos medios de comunicación que modifican radicalmente los modos de producción, circulación y recepción de las imágenes.

En este sentido, Mirzoeff (2003) plantea que la reivindicación de la fotografía como reflejo de lo real ya no puede sostenerse a partir de las transformaciones en el dispositivo fotográfico. Por su parte, Robins afirma que la muerte de la fotografía y la llegada de la era de la postfotografía "representa una respuesta al desarrollo de la nueva tecnología electrónica digital para la grabación, manipulación y almacenamiento de imágenes” (Robins, 1997, p. 49).

De esta manera, los cambios en la cultura de la imagen se asocian y se interpretan en términos de revolución tecnológica, y muchos observan estos cambios en términos de mayor flexibilidad y libertad para la creación de imágenes, a partir de lo cual, la fotografía se liberará de su inherente automatismo y realismo (Robins, 1997, p. 50).

Los discursos sobre la postfotografía se apoyan en la idea de un profundo cambio en las concepciones de la realidad, el conocimiento y la verdad, y a partir de ello se afirma que con la postfotografía se cae el velo a través del cual se creyó en la representación fiel de lo real, con lo cual debemos olvidar las distinciones entre imaginario y real.

En el contexto de los discursos del posmodernismo, muchos autores han señalado que la revolución cultural y tecnológica de la imagen es el centro de la transición de la condición de modernidad a la posmodernidad, en este sentido Mitchell (1992) afirma que la imagen digital se adapta oportunamente a los proyectos de la era posmoderna, en la que se cuestionaba la primacía del mundo material sobre la imagen, y la propia existencia del mundo real: 'el mundo de la simulación y de los simulacros' (Baudrillard, 2001), erosión del principio de realidad: tecnoesferaposreal, la denomina Robins (1997).

Desde este punto de vista, la llegada de la postfotografía nos liberaría de "las verdades de la fotografía”, y permitiría otro entendimiento de la relación entre lo imaginario y lo real, por ello Robins (1997) plantea que es necesario reconsiderar los usos de las fotografías y la referencia existencial de las imágenes del mundo en la intersección de una cultura postfotográfica. 
A este nuevo paradigma de la fotografía, Ritchin (2010) propone denominarlo hiperfotografía, que sería más que 'post' un campo en expansión en donde la representación de lo visible puede ahora transmitirse, recontextualizarse, fabricarse y modificarse (Ritchin, 2010, p. 129).

En un sentido similar, Joan Fontcuberta (2007) afirma que es necesario abandonar la idea arraigada en la sociedad - desde su invención- de que la fotografía es el resultado de un procedimiento natural, automático, espontáneo, a través del cual se puede copiar la naturaleza con la máxima precisión y fidelidad sin dependencia de las habilidades de quien la realiza, carente de filtros culturales e ideológicos, pues detrás de esa supuesta transparencia se esconde todo el dispositivo que hace que interpretemos la fotografía desde el lugar de la transparencia.

Fontcuberta (2012) advierte que la necesidad de creencia en la fotografía, fundamentada en la génesis técnica del dispositivo, se vio corrompida con el surgimiento de las tecnologías digitales, y en base a esto sentencia que asistimos a la muerte de la fotografía y a un cambio de paradigma que supone el paso de lo analógico a lo digital, en el que la fotografía digital ha asumido las antiguas aplicaciones de la fotografía tradicional. Así, los valores de lo documental (registro, verdad, memoria, archivo, identidad, etcétera) que acompañaron a la fotografía durante los siglos XIX y XX van camino a la virtualidad en el siglo XXI con la fotografía digital. Esto supone un cambio de naturaleza que está relacionado, a su vez, a los cambios en la cultura, la sociedad, la política, y la economía:

La fotografía argéntica aporta la imagen de la sociedad industrial y funciona con los mismos protocolos que el resto de la producción que tenía lugar en su seno. La materialidad de la fotografía argéntica atañe al universo de la química, al desarrollo del acero y del ferrocarril, al maquinismo y a la expansión colonial incentivada por la economía capitalista. En cambio, la fotografía digital es consecuencia de una economía que privilegia la información como mercancía, los capitales opacos y las transacciones telemáticas invisibles [...] Responde a un mundo acelerado, a la supremacía de la velocidad vertiginosa y a los requerimientos de la inmediatez y globalidad (Fontcuberta, 2012, p. 12).

De esta manera, Fontcuberta agrega que la fotografía digital se inscribe en una segunda realidad o realidad de ficción, y supone un proceso progresivo de 
desmaterialización, la impresión de la imagen ya no es un requisito de existencia, el actual soporte de la fotografía digital es la pantalla. Esto produce un cambio en el contrato visual, puesto que en este proceso de desmaterialización, la imagen pasa a depender de un programa de tratamiento para visualizarse, por lo tanto siempre está procesada.

Como podemos ver, los cambios tecnológicos que comenzaron en la década de 1990 van modificando las prácticas fotográficas, pero estas transformaciones no sólo afectaron a las prácticas, sino que también pusieron en debate las nociones mismas que sirvieron para pensar la especificidad de la imagen fotográfica, que como vemos ha llevado a distintos teóricos a plantear la muerte de la fotografía y la llegada de una nueva categoría de imágenes, a las que han denominado postfotográficas.

En muchos de los argumentos que revisamos en este apartado, subyace la idea de la muerte de la fotografía a partir del cambio en su naturaleza técnico-indicial, a partir de lo cual se afirmaba que la fotografía entraba a una realidad de ficción. No obstante, y si bien los cambios en las prácticas fotográficas -tanto en el nivel de la producción, como en la circulación y recepción- se han modificado profundamente en la actual cultura digital, algunos de los diagnósticos no se han producido con la intensidad anunciada, principalmente en las cuestiones relacionadas a 'la realidad de ficción' y a la pérdida de credibilidad de la imagen. Las tecnologías digitales permiten nuevas intervenciones sobre las imágenes, pero no rompen de manera absoluta las nociones de registro. Las fotografías digitales adquieren hoy una fuerte presencia en los intercambios comunicativos y con ello, es cierto, cambian los modos de hacer y de recibir las fotografías, los registros ya no parecen responder al esto ha sido, para hacer perdurar un acontecimiento importante, sino que entran en la nueva lógica de la interconectividad tecnológica, se transforman en un medio de primer orden para el intercambio de experiencias presentes.

Nos hallamos en la actualidad ante la necesidad de reflexionar y abrir nuevos interrogantes sobre la fotografía digital, reconsiderando la naturaleza de su dispositivo y su cualidad de medio, en la actual esfera de las mediatizaciones contemporáneas. 


\section{Reflexiones finales}

Como podemos observar, los debates sobre las tecnologías digitales pusieron los cambios en el dispositivo fotográfico en un lugar central en la reflexión de cómo estas transformaciones cambiarían nuestra concepción de la imagen fotográfica. La fotografía analógica inauguró las imágenes técnicas, adoptando el proyecto visual moderno que establecía a la perspectiva como norma de representación, su gran novedad fue la posibilidad de inscribir la luz en una sustancia fotosensible. En esta conjunción, la fotografía recibía dos cualidades respectivas, la semejanza y la huella, lo icónico y lo indicial. Pero con la digitalización dicha materialidad de la huella queda eliminada y con ello parecería que se disuelve su indicialidad. Esta desmaterialización de la imagen ha llevado a replantear nuevamente el estatuto de la fotografía, donde parecería persistir su carácter icónico (es decir su grado de semejanza con lo que representa), donde cada vez se habla más de su aspecto simbólico; y la indicialidad entra en el centro del debate, a partir de ser negada o desplazada al acto de producción de la imagen y a lo performativo. A lo anterior se suma un aspecto, muchas veces destacado para argumentar sobre la pérdida de la credibilidad de la fotografía, sobre las técnicas de edición (y manipulación) de la imagen y la creación de imágenes por ordenador. Revisemos algunas de estas cuestiones, considerando la lógica de los nuevos medios de comunicación, que han transformado profundamente los modos de producción, circulación y recepción de las imágenes. Nos interesa aquí, principalmente, pensar en los cambios en las prácticas amateurs (la producción de los internautas), en la nueva esfera de comunicaciones en red.

En primer lugar, y en cuanto a la indicialidad, si bien la digitalización del dispositivo ha cambiado la naturaleza de la imagen en cuanto huella; aun hoy podemos seguir hablando de prácticas fotográficas basadas en el registro del acontecimiento. En este sentido, Mario Carlón plantea que en muchos casos podemos seguir hablando de fotografías contemporáneas de registro, es decir, indiciales, pero advierte que se trataría de una indicialidad débil: "[...] como vivimos en una época de fin de la inocencia y de crisis de la indicialidad, donde toda fotografía puede ser editada y alterada, la que los internautas han consagrado es una indicialidad débil, siempre a punto de ser puesta en discusión” (Carlón, 2016, p. 49). 
Al momento de la toma, el dispositivo fotográfico digital parecería operar de la misma manera que el analógico, sin embargo, la nueva técnica realiza un registro de la escena a través de una información codificada que nos permite ver y retocar en el mismo momento la imagen y hacerla circular. No obstante, no podemos afirmar que en la fotografía digital la necesidad de copresencia del referente y el acto de registro se hayan perdido, en todo caso se utiliza la categoría fotografía para nombrar imágenes que en realidad no lo son, las imágenes creadas digitalmente con apariencia fotográfica no son fotografías por que precisamente no responden a la referencia, al registro del referente. De aquí se desprenden dos puntos importantes a considerar para reflexionar sobre los cambios actuales en la fotografía contemporánea: las posibilidades de edición y los cambios en la circulación.

En primer lugar, un aspecto crucial que se puso en juego en el debate de los efectos de la digitalización fotográfica fue el de las posibilidades de editar y manipular la fotografía. En incontables casos cuando se refieren a los cambios en la credibilidad de la imagen digital, se hace alusión al conocimiento de las técnicas de edición de la imagen que los usuarios han adquirido, junto a las posibilidades de crear imágenes por ordenador.

Sabemos que en la fotografía analógica las posibilidades de edición ya eran posibles, pero se relegaban al ámbito especializado. Dichas posibilidades vienen hoy a acrecentarse con los programas de edición, y lo que resulta crucial en este punto es que los mismos dispositivos traen en sus sistemas aplicaciones que posibilitan e invitan a generar cambios en la imagen, a partir de las cuales los usuarios pueden manipular sus fotos de manera sencilla utilizando ciertas opciones que le proporciona el artefacto. Sin embargo, la fotografía no pierde con ello su función de registro y, asimismo, podemos pensar que las técnicas de edición, más que falsear lo real, a simularlo, vienen a estetizar la vida cotidiana.

Por lo tanto, más allá de la cuestión de las posibilidades de edición de la imagen y la supuesta pérdida de credibilidad, nos parece que lo central no es focalizarse en ello como si de una 'pérdida de principios' se tratase, sino interrogarnos sobre lo que estos cambios de naturaleza suponen en el pensamiento sobre la representación a través de fotografías. En este sentido, el estado actual de las reflexiones sobre la fotografía contemporánea se ve ante el desafío de pensar las 
prácticas sociales y los diferentes usos de la fotografía en las distintas áreas de la praxis humana a la luz de la nueva lógica de la imagen numérico-binaria y los nuevos medios de comunicación con base en internet.

Con los nuevos medios de comunicación el presente se expande en nuestra experiencia, y se transforma en la categoría temporal donde se apoyan las principales prácticas comunicacionales (Carlón, 2016). Con ello, se acorta la distancia temporal entre los flujos perceptivos, lo que se ve modificado principalmente es el modo y el tiempo en que dichas imágenes comienzan a circular, y con ello la intencionalidad del acto fotográfico, ya no se trata de un registro para hacer perdurar lo que desaparece sino una instancia presente de participación, y con esto nos referimos no sólo a las imágenes creadas con fines periodísticos o de actualidad pública -imágenes que antaño hacían circular sólo los medios masivos- sino que ahora se reconfigura la participación de los individuos, cuyas imágenes circulan en los nuevos medios.

Los usuarios se transforman en productores de mensajes y resignifican los discursos de los medios masivos, como así también estos se hacen eco y reutilizan los de los usuarios. Comunicaciones que ya no se dan únicamente de manera descendente (de arriba hacia abajo) sino también de manera ascendente (de abajo hacia arriba) ${ }^{1}$. Sobre esto Carlón especifica que una teoría de la comunicación en la contemporaneidad debe tener en cuenta estos cambios:

Un modelo teórico operativo, desde nuestro punto de vista, debe ser capaz de dar cuenta de una circulación que cada vez más se expande horizontalmente y da, a su vez, más saltos "hacia arriba" y "hacia abajo" estableciendo complejos cambios de escala comunicativos y en la mediatización (Carlón, 2015, p. 7).

Como advertíamos, considerando las nuevas lógicas de los medios de comunicación digitales, es posible reparar en algunas cuestiones. La primera es el predominio del presente como categoría temporal, un punto no menor que

\footnotetext{
1 Para un análisis en profundidad de la reconfiguración de estas instancias discursivas 'ascendentes' y descendentes' son interesantes los análisis de Mario Carlón (2012) sobre la televisación de la votación en el Senado por el matrimonio igualitario en Argentina, en donde los distintos medios adquirieron diferentes estrategias enunciativas haciendo públicos los comentarios de los usuarios de las redes. De la misma manera, José Pablo Concha (2011) pensando en los cambios en la fotografía contemporánea, repara también en que los nuevos medios abren las comunicaciones a dos direcciones.
} 
modifica la producción, la circulación y la recepción de las imágenes. Las fotografías se crean para ser compartidas instantáneamente en las redes sociales. Un segundo punto importante que surge de la pérdida de materialidad de la fotografía es que hoy las imágenes digitales pueden estar presentes en simultáneo en diferentes “espacios”, donde se diluye la idea de un original. En relación a ello José Pablo Concha afirma: “[...] lo importante es que se encuentra en la red y esto significa que está en el lenguaje que unifica toda acción humana contemporánea” (Concha, 2011, p. 222), haciendo referencia con ello al lenguaje numéricobinario.

Esta pérdida de materialidad permite pensar también otras cuestiones, entre ellas que en la fotografía analógica el acto fotográfico parecía estar en general reservado a registrar (y si se quiere a consagrar) acontecimientos importantes (ya sean públicos o privados). La fotografía digital contemporánea se ha transformado hoy en una parte imprescindible de la vida cotidiana, cada instante por más insignificante es fotografiable y merecedor de estar en las redes.

En este sentido, podemos observar una especie de impulso autobiográfico, articulando la primera persona, y rompiendo con el uso generalizado de la tercera persona como la forma ideal del registro fotográfico a través de la mediación del dispositivo técnico indicial. Una primera persona que testimonia y deja su huella como un lazo con lo viviente, con la experiencia, una experiencia que no rompe con lo real en cuanto a lo imaginario sino con la forma en la que históricamente se buscó representarlo, como afirma Gonzalo Aguilar:

podemos pensar la encrucijada actual como una lucha entre la tercera y la primera persona en la que unos organismos vivos cualesquiera intentan dejar su huella: la cámara misma se transforma en un organismo, en una prótesis, porque ya no vivimos fuera de la imagen y todos somos hacedores de imágenes digitales (Aguilar, 2015, p.78).

Como podemos ver, pese a los cambios en el dispositivo, muchas características y funciones sociales, continúan vigentes en la fotografía digital contemporánea. Otro rasgo que podemos destacar en cuanto a continuidad es la idea de corte espacio - temporal. La imagen continúa marcando una discontinuidad con el acontecimiento en cuanto a duración. No obstante, son puestas a circular constante e inmediatamente en las redes sociales, las que les dan un marco 
interpretativo, un contexto de lectura: páginas personales, perfiles de redes sociales, en las que muchas veces las imágenes van acompañadas no sólo de comentarios de sus autores y los participantes de su círculo en red, sino también de fechas, horarios e incluso, a veces, ubicación. La palabra y la imagen en las redes sociales aparecen estrechamente relacionadas.

Ese contexto, dado por la palabra y los sitios donde la fotografía circula, viene acompañado de mensajes escritos: comentarios que proporciona el que la comparte y luego la respuesta de quien mira la fotografía en la red. Se trataría, como afirma Fontcuberta (2016), de imágenes conversacionales.

Podemos decir, incluso, que los usuarios de las redes, construyen imágenes para las mismas, y adquieren la temporalidad reinante de nuestro tiempo. Muchas de las fotografías creadas en los dispositivos -e incluso ya compartidas en los nuevos medios- no están destinadas al recuerdo, sino que a veces quedan condenadas al olvido. Se trata, en muchos casos, de instantes fotografiados y compartidos en y para el presente. Una furia de imágenes inmateriales (Fontcuberta, 2016) efímeras, propensas a no ser vistas nuevamente.

En base a estas cuestiones señaladas, podemos concluir entonces que los cambios en el dispositivo fotográfico con la digitalización no conllevan la perdida de la contigüidad con el referente. La imagen fotográfica digital continúa estando motivada por el referente real que estuvo delante del dispositivo. Por lo tanto, la iconicidad se genera en función de la indicialidad.

El principal cambio en la contemporaneidad es en la circulación de los mensajes en los nuevos medios de comunicación. Y desde ese eje debemos reflexionar sobre los cambios en los modos de producción y recepción de la imagen fotográfica, donde se acorta la distancia temporal entre el momento de producción y el momento de recepción. La fotografía se abre en la actualidad a una multiplicidad de posibilidades que ha generado su expansión en la sociedad como parte constituyente de las experiencias, e incluso como una experiencia en sí misma. La mayor cantidad de mensajes y contenidos que recibimos y enviamos a través de las redes sociales (WhatsApp, Twitter, Facebook, Instagram) son fotografías. Modificadas, retocadas, recortadas, compartidas, comentadas, cuestionadas; las fotografías se han convertido hoy en una parte imprescindible de las nuevas 
formas de comunicación en los medios digitales, transformándose ella misma en un mensaje.

La fotografía no ha muerto, por el contrario, se ha expandido y a partir de ello surgen nuevas formas comunicacionales que transforman las prácticas y con ello, la idea y los modos de representación.

\section{Referencias bibliográficas}

Aguilar, G. (2015) Más allá del pueblo: imágenes, indicios y políticas del cine. Buenos Aires: Fondo de Cultura Económica.

Baudrillard, J. (2001) La precisión de los simulacros (1983). WALLIS, B. (Comp.) Arte después de la modernidad. Nuevos planteamientos en torno a la representación. Madrid: Akal.

Barthes, R. (2005) La cámara lúcida. Buenos Aires: Paidós.

Bazin, A. (2004) Ontología de la imagen fotográfica. ¿Qué es el cine? Madrid: Rialp.

Berger, J. (1998) Apariencias. Berger, J. y Mohr, J. (1998) Otra manera de contar. Murcia: Editorial Mestizo.

Carlón, M. (2015) Público, privado e íntimo: el caso chicas bondi y el conflicto entre derecho a la imagen y la libertad de expresión en la circulación contemporánea. Castro, P. (Ed.) Dicotomía público/privado: estamos no camino certo? Maceió: EDUFAL.

Carlón, M. (2016) Registrar, subir, comentar, compartir: prácticas fotográficas en la era contemporánea. Corro, P. y Robles, C. (Eds.) Estética, medios y subjetividades. Santiago: Universidad Pontificia Católica de Chile.

Carlón, M. (2012) En el ojo de la convergencia. Los discursos de los usuarios de Facebook durante la transmisión televisiva de la votación de la ley de matrimonio igualitario. Carlón, M. y Fausto Neto, A. (Comp.) La Política de los internautas. Buenos Aires: La Crujía.

Carlón, M. (2014) ¿Del arte contemporáneo a una era contemporánea? Rovetto, F. y Reviglio, M. (comp.) Estado actual de las investigaciones sobre mediatizaciones. Centro de Investigaciones sobre mediatizaciones UNR. Rosario: UNR Editora. Disponible en: http://www.cim.unr.edu.ar/archivos/cuadernodelcim2.pdf (última consulta: 18/8/2016).

Carlón, M.y SCOLARI, C. (Eds) (2009). El fin de los medios masivos. Buenos Aires: La Crujía.

Concha, J. (2011) La desmaterialización fotográfica. Santiago de Chile: Edición Metales Pesados.

Dubois, P. (2008) El acto fotográfico y otros ensayos. Buenos Aires: La Marca. 
Fontcuberta, J. (2007) El Beso de Judas. Fotografía y Verdad. Barcelona: Gustavo Gili.

Fontcuberta, J. (2012) La cámara de pandora. La fotografía después de la fotografia. Barcelona: Gustavo Gili.

Fontcuberta, J. (2016) La furia de las imágenes. Notas sobre la postfotografía. Barcelona: Galaxia Gutenberg.

Krauss, R. (2002) Lo fotográfico por una teoría de los desplazamientos. Barcelona: Gustavo Gili.

Lister, M. (Comp.) (1997) La imagen fotográfica en la cultura digital. Barcelona: Paidós.

Mirzoeff, N. (2003) Una introducción a la cultura visual. Barcelona: Paidós.

Mitchell, W. (1992) Thereconfiguredeyes: visual truth in the post-photographic era. Cambridge: MassMitPress.

Peirce, C. (1987) Obra lógico semiótica. Madrid: Taurus.

Ritchin, F. (2010) AfterPhotography. WW Norton \& Co.

Robins, K. (1997) ¿Nos seguirá conmoviendo una fotografía? en Lister, M. (Comp.) La imagen fotográfica en La cultura digital. Barcelona: Paidós.

Schaeffer, J. (1990) La imagen precaria. Del dispositivo fotográfico. Cátedra: Madrid.

Sontag, S. (1977) Sobre la fotografía. Buenos Aires: Alfaguara.

Verón, E. (1997) De la imagen semiológica a las discursividades. El tiempo de una fotografía. Veyrat-Masson, I. y Dayan, D. (Ed.) Espacios públicos en imágenes. Barcelona: Gedisa.

Verón, E. (2013) La semiosis social, 2: ideas, momentos, interpretantes. Buenos Aires: Paidós. 